nodules. There may or may not be an associated eczematous eruption. The lesions classically consist of single or multiple nodules situated on the extremities, especially on the anterior surfaces of the thighs and legs. A linear arrangement of the lesion is common. Among various skin manifestations in HIV positive patients, prurigo nodularis was observed in $1.8 \%$ and $6.5 \%$ of patients in two studies. ${ }^{12}$

The cause of prurigo nodularis is unknown although emotional stress can be a contributory factor, as seen in some apparently healthy HIV negative subjects. Around $80 \%$ of patients (non HIV positive) are atopic, although, often, there is no eczematous eruption present. In the remaining $20 \%$, the condition is said to start after an insect bite. No such precipitating factors were found in the case presented. The classical symptoms of intense pruritus and nodules were present. New nodules may develop from time to time. Nodules may remain pruritic indefinitely although some may regress spontaneously to leave scars.

The large, more or less symmetrical nodules along with the history associated with the pruritus, established the diagnosis. The histology findings are considered to be consistent with prurigo nodularis but are by no means diagnostic.

Treatment of this condition can be by local application of steroids, ultraviolet phototherapy, Psoralen photochemotherapy, benoxaprofen, thalidomide, and direct injection of the nodules with a steroid can often be helpful. The latter was not attempted in the case as the lesions were too widespread, making it technically difficult to perform. In our case, the patient was treated using ultraviolet B phototherapy, which has previously been shown to be effective in pruritic HIV-associated dermatoses. ${ }^{3}$ This resulted in an improvement in both his signs and symptoms. Despite the effectiveness of the treatment, one should be cautious about prolonged use of ultra violet B phototherapy, because of the risk of developing skin malignancies, particularly in immunocompromised patients.

ARABINDA KUNDU A A H WADE Department of GU Medicine, Coventry and Warwickshire Hospital, Stoney Stanton Road, Coventry CV1 $4 \mathrm{FH}$ A ILCHYSHYN

Department of Dermatology, Walsgrave Hospital, Coventry CV2 2DX

Address correspondence to: $\operatorname{Dr} A$ Kundu.

1 Wambugu P, Plummer FA, Anzala AO, Gilks C, Bosire $M$, Ngugi EN. Clinical manifestations of HIV-1 infection among women working as prostitutes in Nairobi. International Conference on AIDS 1990 20-23 June; 6(1):260 (abstract no Th.c.543)

2 Anzala A, Wambugu P, Bosire M, Ngugi EN; Waiyaki P, Plummer FA. The rate of development of HIV-1 related illness in women with a known duration of infection International Conference on AIDS 1990 20-23 June; 6(1):143 (abstract no Th.c.37)

3 Penney NS. Pruritic papular and follicular eruptions in: Marks R ed, Skin Manifestations of AIDS: London Martin Dunitz 1990; 143.

Presented as a poster at a meeting of the Medical Society of Venereal Diseases, Liverpool, May 1994.

Accepted for publication 25 October 1994 Pancreatitis associated with aerosolised
pentamidine

Pentamidine is widely used for both prophylaxis and treatment of Pneumocystis carinii pneumonia (PCP) and pancreatitis is a recognised adverse effect of this agent. This is generally seen during treatment of established $\mathrm{PCP}^{1-5}$ and may occasionally be fatal. ${ }^{67} \mathrm{We}$ describe a case of acute pancreatitis following the use of monthly aerosolised pentamidine for prophylactic purposes.

A 29 year old man found to be infected with human immunodeficiency virus (HIV) in 1987 was started on co-trimoxazole for primary PCP prophylaxis in September 1991 as his absolute CD4+ cell count fell to $200 \times$ 10\%/. In March 1993 this had to be discontinued on account of severe neutropenia $(0.37$ $\left.\times 10^{9} / 1\right)$. He was then prescribed nebulised pentamidine $300 \mathrm{mg}$ once a month. His CD4+ cell count had dropped to $10 \times$ $10^{6} / 1$ by March 1994 but he remained otherwise well with no AIDS defining illness. $\mathrm{He}$ was also unable to tolerate zidovudine but required long term acyclovir for recurrent herpes simplex and fluconazole for oral candidiasis. In June 1994, he was admitted to hospital with severe upper abdominal pain associated with nausea six days after his monthly pentamidine.

Clinically, it was felt that he had acute pancreatitis with no signs of any disseminated opportunistic infection. Serum amylase was $1116 \mathrm{U} / 1$ (normal range 0-95). Blood glucose, renal function and liver enzymes were normal. Serum calcium $2.13 \mathrm{mmol} / 1$ (normal range $2 \cdot 26-2 \cdot 60$ ). Blood cultures were sterile. An abdominal ultrasound scan revealed a very oedematous pancreas with surrounding fluid but no gall stones. Abdominal CT did not reveal any neoplastic or other pathology. CT of the head (done as he complained of headaches at one stage) was also normal. His symptoms settled down with conservative treatment, the serum amylase fell to $235 \mathrm{U} / 1$ and he was allowed home a week later.

$\mathrm{Hart}^{8}$ reported the case of a man who received a 21 day course of intravenous pentamidine for PCP. He was subsequently given biweekly nebulised pentamidine $60 \mathrm{mg}$ and a year later developed acute pancreatitis. Prior exposure to sulpha-containing drugs has been recognised as a risk factor ${ }^{2}$ but to our knowledge, this is the first reported case of pancreatitis due to aerosolised pentamidine when used for primary PCP prophylaxis in a relatively low dose in an individual never exposed to the agent in a therapeutic dose intravenously or otherwise in the past.

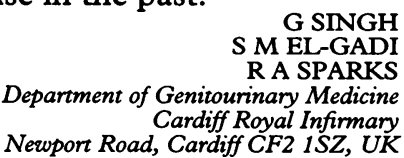

1 Murphey SA, Josephs AS. Acute pancreatitis associated with pentamidine therapy. Arch Intern Med 1981;141: 56-8.

2 O'Neill MG, Selub SE, Hak LJ. Pancreatitis during pentamidine therapy in patients with AIDS. Clinical Pharmacy 1991;10:56-8. 
3 Herer B, Chinet T, Labrune S, et al. Pancreatitis associated with pentamidine by aerosol (letter). BMF 1989, 298:605.

4 Salmeron SG, Petitpretz P, Katlama C, et al. Pentamidine and pancreatitis (letter). Ann Intern Med 1986;105: $140-1$

5 Klatt EC. Pathology of pentamidine-induced pancreatitis. Arch Pathol Lab Med 1992;116:162-4.

6 Zuger A, Wolf BZ, El-Sadr W, et al. Pentamidineassociated fatal acute pancreatitis. $\mathfrak{F A M A} 1$ 1986;256: 2383-5.

7 Kumar S, Schnadig VJ, MacGregor MG. Fatal acute pancreatitis associated with pentamidine therapy (letter) Am $\mathcal{f}$ Gastroenterol 1989;84:451-3.

8 Hart CC. Aerosolised pentamidine and pancreatitis (letter). Ann Intern Med 1989;111:691.

Accepted for publication 30 October 1994

\section{Screening for herpes simplex virus in} infertile women

Herpes simplex virus (HSV) infection is among the most common causes of sexually transmitted diseases worldwide. Symptomatic infection with $\mathrm{HSV}$ causes much physical discomfort, psychological disorders and interferes with sexual relations. ${ }^{1}$ Subclinical infections, which are not infrequent, contribute to the sexual transmission of the disease. Besides, transmission of the virus from mother to child when passing through the birth canal may cause severe disease in the neonate, resulting with death or serious sequelae. $^{23}$

Two hundred and seventy nine infertile women attending an in vitro fertilisation and embryo transfer (EVF-ET) programme in the Ege University Hospital (Turkey) were included in the study. The patient group consisted of asymptomatic women from the middle socioeconomic class, aged between 25-40 years, having no history of genital herpes. Endocervical specimens were obtained from these women on their first visit to the hospital. Specimens were tested by a commercially available direct immunofluorescence test kit (Pathfinder, Kallestad Laboratories, USA), according to the manufacturer's recommendations.

Forty one out of 279 specimens (14.69\%) were considered inadequate, owing to insufficient number of cells. Of the remaining 238, three were positive for HSV-1 $(1 \cdot 26 \%), 11$ for HSV-2 (4.62\%), and one was both HSV-1 and -2 positive $(0 \cdot 42 \%)$. The overall positivity rate for HSV was $6 \cdot 30 \%$.

Genital HSV infections have shown a rising trend all over the world in recent years. However, it is difficult to assess the real percentage of genital herpes due to the frequency of subclinical infections. Koutsky et $\mathrm{al}^{4}$ indicated that, in a patient group having serologic or virologic evidence of HSV-2, $22 \%$ had symptomatic clinical genital infection, $16 \%$ reported past episodes of genital herpes, but were asymptomatic at the time material was collected, while $62 \%$ had unrecognised infection, of whom $4 \%$ had asymptomatic viral shedding at the time of examination. In another study, Kulhanjian et $a l^{5}$ stated that, detailed questioning of the participants revealed that only $35 \%$ of the women, and
$46 \%$ of the men with serologic evidence of HSV-2 infection had had symptoms of genital herpes.

In the present study, none of the patients had past or present evidence suggestive of genital herpes. However, $6 \cdot 3 \%$ were asymptomatically shedding the virus. Barlas et $a l^{6}$ from Turkey, detected the HSV positivity rate in asymptomatic young women from a low socioeconomic class as $7 \cdot 7 \%$. In another study from Turkey, ${ }^{7} \mathrm{HSV}-2$ incidence in sex workers was found to be $6 \%$.

As stated by several authors, asymptomatic infection plays a major role in the transmission of the virus to seronegative sexual partners or more importantly, to the neonates. ${ }^{3}$

The development of antiviral therapy has made it possible to improve the outcome of the neonatal disease and the knowledge of the epidemiology of herpes infections in a certain population is essential to take preventive measures. ${ }^{3}$

The outcome of the pregnancy and the survival of the newborn in an IVF-ET programme bears both physical and moral importance. Hence, the significance of genital herpes in such a patient group increases.

The data in the present study indicate that genital HSV infection is a challenge in our population as in many others, and that HSV2 and less frequently HSV-1 can produce asymptomatic infections. Also, dual infections with both viruses can be encountered, although very rare.

Since there is no control programme on a national basis at present in our country, further studies on different patient groups are needed to disclose the epidemiological distribution of genital HSV infections. Meanwhile, screening of patients attending IVF-ET programmes, before any intervention is planned, may be beneficial for applying preventive measures beforehand.

$$
\begin{array}{r}
\text { D DERELI } \\
\text { Department of Experimental Surgery and Research } \\
\text { E ERTEM } \\
\text { Department of Clinical Bacteriology and Infectious Diseases } \\
\text { E N TAVMERGEN } \\
\text { Center for Family Planning and } \\
\text { Infertility Research and Treatment } \\
\text { D SERTER } \\
\text { E TAVMERGEN } \\
\text { Department of Clinical Bacteriology and Infectious Diseases } \\
\text { Center for Family Planning and } \\
\text { Infertility Research and Treatment } \\
\text { F KOÇYGIT } \\
\text { Center for Family Planning and } \\
\text { Infertility Research and Treatment } \\
\text { R CAPANOGLU } \\
\text { Center for Family Planning and } \\
\text { Infertility Research and Treatment, } \\
\text { Ege University, Faculty of Medicine } \\
35100, \text { Bornova Izmir, Turkey }
\end{array}
$$

Address correspondence to: Dr D Serter, Ege University, Faculty of Medicine, Department of Clinical Bacteriology and Infectious Diseases, 35100 Bornova, Izmir, Turkey

We are grateful to Ahmet Hüdaverdi and Ali Köse for technical assistance.

1 Mertz GJ. Genital herpes simplex virus infections. Med Clin North Am 1990;74:1433-54.

2 Brown ZA, Benedetti J, Ashley R, et al. Neonatal herpes simplex virus infection in relation to asymptomatic maternal infection at the time of labor. $N$ Engl $f \mathrm{Med}$ 1991;324:1247-52

3 Forsgren M. Genital herpes simplex virus infection and incidence of neonatal disease in Sweden. Scand $\mathcal{f}$ Infect Dis 1990;Suppl 69:37-41. 